\title{
Electrochemical Impedance Spectroscopy Study of the interaction of Supported Lipid Bilayers with Free Docosahexaenoic Acid
}

\author{
Kiera R. Flynn'1,2, M Leigh Ackland ${ }^{1,2}$ and Angel A.J. Torriero ${ }^{2 *}$ \\ ${ }^{1}$ Centre for Cellular and Molecular Biology, Deakin University, Australia \\ ${ }^{2}$ School of Life and Environmental Sciences, Deakin University, Australia
}

*Corresponding author: Angel AJ Torriero, School of Life and Environmental

\section{Research Article}

Volume 2 Issue 3

Received Date: September 14, 2018

Published Date: October 01, 2018

Sciences, Deakin University, Burwood, Victoria 3125, Australia, Tel: +613 9244 6897; Email: angel.torriero@deakin.edu.au

\section{Abstract}

Docosahexaenoic acid (DHA) is the most abundant polyunsaturated omega-3 fatty acid found in mammalian neuronal cell membranes. Although DHA is known to modify the physicochemical properties of plasma membranes, potentially influencing their function, little is known about how this interaction with phospholipid bilayers happens. This study presents a detailed electrochemical impedance spectroscopy (EIS) analysis of the interaction between free DHA with 1palmitoyl-2-oleoyl-sn-glycero-3-phosphocholine (POPC) supported lipid bilayer (SLB) and POPC mixed with anionic phospholipids, such as phosphatidylinositol (PI) and phosphatidylserine (PS)-SLBs. Combination of EIS data with those of quartz crystal microbalance with dissipation monitoring for the same SLB, made possible the predictions of changes in the dielectric constant $\left(\Delta \varepsilon_{\mathrm{m}}\right)$ of the different SLBs after treatment with different DHA concentrations. The POPC SLBs $\Delta \varepsilon_{\mathrm{m}}$ was estimated to increase with increasing DHA concentration. However, the response of POPC-PI and POPC-PS SLBs showed a completely different response after the addition of DHA, suggesting the presence of a substitution/exchange process occurring after the DHA addition. Furthermore, the $\Delta \varepsilon_{\mathrm{m}}$ of PS-containing SLBs formed in the presence of $\mathrm{Ca}^{2+}$ was also studied, and the results compared to those obtained with PS-containing SLBs formed in the absence of $\mathrm{Ca}^{2+}$. The results indicated that the incorporation of DHA in the POPC-PS SLBs is function of the concentration of PS and presence of calcium ions in the mentioned SLB.

Keywords: Electrochemical Impedance Spectroscopy; Supported Lipid Bilayers; Docosahexaenoic Acid 


\section{Medicinal \& Analytical Chemistry International Journal}

Abbreviations: DHA: Docosahexaenoic Acid; EIS: Electrochemical Impedance Spectroscopy; POPC: 1palmitoyl-2-oleoyl-sn-glycero-3-phosphocholine; SLB: Supported Lipid Bilayer; PI: Phosphatidylinositol; PS: Phosphatidylserine; PUFA: Polyunsaturated Fatty Acid; PC: Phosphatidylcholine; QCM-D: Quartz Crystal Microbalance; TBS: Tris Buffered Saline; SUV: Small Unilamellar Vesicles; CPEs: Constant Phase Elements; CMC: Critical Micellar Concentration.

\section{Introduction}

The omega-3 fatty acid docosahexaenoic acid (DHA) is an essential polyunsaturated fatty acid (PUFA) for the development and function of the mammalian brain $[1,2]$. Studies have shown that DHA supplementation improves early childhood brain development including increased attention span, processing speed and cognitive ability in humans [3]. DHA supplements also improves cognitive function and memory in ageing subjects compared to nonsupplemented controls the mechanisms by which DHA improves cognitive ability is unclear but is thought to be linked to the effect of DHA on the physicochemical properties of the neuronal plasma membrane $[4,5]$.

Outside of the brain, changes to the membrane lipid composition caused by PUFAs have been reported to result in changes to membrane properties that may provide many therapeutic advantages. Reports have highlighted the clinical application of DHA as an immunosuppressive agent due to its ability to rapidly alter phospholipid composition without an associated production of inflammatory eicosanoids, known to occur with omega-6 fatty acids [6]. PUFAs can inhibit $\mathrm{T}$ cell activation in Jurcat $T$ cells, speculated to be a consequence of the PUFAs selectively altering detergent resistant membrane domains within the lipid bilayer [7]. Furthermore, several studies demonstrated that altering the lipid fatty acid composition of tumors cells enhanced sensitivity to anti-cancer treatments, where incubation of L-1210 murine leukemia cells with DHA improved the sensitivity of cells to the cytotoxic effects of chemotherapy drug, adrenomycin $[8,9]$. This was later shown to be true in P388 cells, to the chemotherapy drug, doxorubicin [10]. Electron spin resonance showed that modifying the membrane fatty acid composition of L1210 cells, caused altered physical properties of the tumor cells, including reduced lipid order and increased fluidity, accounting for the increased sensitivity to chemotherapy drugs [11]. The evidence of these DHA-linked responses emphasizes the importance of understanding the molecular mechanisms of DHA on lipid properties within the plasma membrane, and ultimately cell function.

Previous studies show that the presence of DHAesterified phospholipids within model membranes causes changes in membrane curvature, [12,13] lipid packing, $[1,2]$ lipid flip-flop, [12] transition temperatures [2,14] and lipid distribution and domain formation [15]. However, there are fewer studies reporting the effect of free-DHA on model membrane properties. Phosphatidylcholine (PC)-containing vesicles have been used to show that free-DHA treatment produced a more disordered and fluid PC membrane [16,17]. This was consistent with another study of 1-palmitoyl-2-oleoyl-snglycero-3-phosphocholine (POPC) SLBs on a quartz crystal microbalance with dissipation monitoring (QCMD) which reported worm-like protrusions from the SLB following high concentration DHA treatment [18]. Our previous studies, which also used the QCM-D technique, were the first reports to show that DHA incorporation into supported lipid bilayers (using various phospholipid compositions) depends on the DHA concentration, the SLB composition (including the presence of flurecent probes) and the presence of calcium ions $[19,20]$.

Previous studies have utilized electrochemical impedance spectroscopy (EIS) to study the formation of SLBs and their interaction with biomolecules [21-23]. EIS is a sensitive technique able to monitor in real-time the membrane integrity and its changes as a consequence of its interaction with different molecules by monitoring the SLBs electrical properties changes. For example, it is the preferred technique to investigate the interaction of poreforming toxin, gramicidin D in model membranes, reporting alterted POPC membrane properties dependent on the gramicidin D concentrations [21]. In addition, the relative activity of formed gramicidin D channels in dihexadecyl dimethyl ammonium bromide/cholesterol membranes based on measured conductance and ion selectivity was also measured [22]. Another study used EIS to show the changes in membranes capacitance and resistance following exposure with antimicrobial peptides [23]. EIS allowed the two peptides modes of actions (carpet or detergent models) to be identified, and provided additional information about the different kinetics and the degree of peptide disruption.

In this work we utilize EIS to investigate the changes in capacitance and resistance of POPC SLBs and POPC mixed with phosphatidylinositol (PI) or phosphatidylserine (PS)-SLBs in the presence and 


\section{Medicinal \& Analytical Chemistry International Journal}

absence of DHA. These EIS data are used together with the thickness of the SLBs to enable a comprehensive analysis of the changes in physicochemical properties of SLBs following DHA treatment. The mentioned thickness is predicted in this work by applying the Voigt-based model to the QCM-D data previously published for the same systems $[19,20]$.

\section{Materials and Methods}

\section{Reagents}

Tris (hydroxymethyl)amino methane (Tris, 99.9\%), sodium chloride $(\mathrm{NaCl}, 99.5 \%)$, hydrochloric acid $(\mathrm{HCl}$, $37 \%)$, sodium hydroxide $(\mathrm{NaOH}, 98 \%)$, chloroform (99\%), ethanol (70\%), docosahexaenoic acid (DHA, 99\%), and calcium chloride $\left(\mathrm{CaCl}_{2}, 99 \%\right)$ were purchased from Sigma-Aldrich. 1-palmitoyl-2-oleoyl-sn-glycero-3-

phosphocholine (POPC), L- $\alpha$-phosphatidylserine (PS) and $\mathrm{L}-\alpha$-phosphatidylinositol-4-phosphate (PI), at $99 \%$ purity were purchased from Avanti Polar Lipids, USA. All these reagents were used as received without further purification.

\section{Solutions}

A $10 \mathrm{mM}$ Tris buffered saline (TBS), containing $100 \mathrm{~m}$ $\mathrm{M} \mathrm{NaCl}$ was prepared using Milli-Q quality water (Millipore, USA). The $\mathrm{pH}$ of these buffer solutions was monitored with a pH meter (Thermo Scientific Orion Dual Star, Australia) and adjusted to $\mathrm{pH} 8$ using either $\mathrm{HCl}$ or $\mathrm{NaOH}$. This $\mathrm{pH}$ value is required to correlate the impedance results with the quartz crystal microbalance data previously reported, $[19,20]$ which is essential to calculate the membrane thickness. An alternative TBS solution was prepared as described before, but with the addition of $2 \mathrm{mmol} \mathrm{CaCl}_{2}$. These buffer solutions were also used as the supporting electrolyte for the electrochemical experiments.

DHA was prepared as a $50 \mathrm{mg} \mathrm{ml}^{-1}$ stock solution in chloroform, and stored in a glass bulb vessel in the dark at $4^{\circ} \mathrm{C}$. The required volume was then aliquoted into a glass vial, the chloroform was evaporated under a nitrogen stream and the vial placed under vacuum atmosphere for 24 hours to evaporate any residue of chloroform. Finally, the dried DHA was dissolved in ethanol to prepare a $10 \mathrm{mg} \mathrm{ml}^{-1}$ DHA solution. This was stored in the dark at $4^{\circ} \mathrm{C}$. All DHA solutions were prepared and stored under nitrogen and the quality of DHA stock solutions were periodically tested for oxidation products using Liquid Chromatography Mass Spectroscopy (Shimadzu, Japan).
The solution was replaced when $\mathrm{M}^{+}$ions different to $\mathrm{m} / \mathrm{z}=327$ was detected. Solutions of $50 \mu \mathrm{M}, 100 \mu \mathrm{M}$ and $200 \mu \mathrm{M}$ DHA were prepared immediately before experiments by taking the DHA from the $10 \mathrm{mg} \mathrm{ml}^{-1}$ ethanolic solution with the use of micropipettes (Bio-Rad, USA) and diluting it with TBS (or TBS $+\mathrm{CaCl}_{2}$ ) to the right concentration. These concentrations were selected as they are typical concentrations used in in-vitro studies [18,24-26]. These concentrations are also consistent with concentrations detected in human plasma following DHA supplementation [27]. Due to the presence of $0.2-0.6 \%$ $\mathrm{v} / \mathrm{v}$ ethanol in the solvent system, the effect of ethanol on the SLB was evaluated. It was observed that ethanol does not affect the SLB structure at this low concentration range, which is consistent with previous reports [21].

Phospholipids solutions of $0.2 \mathrm{mg} \mathrm{ml}^{-1}$, POPC, PI and PS, were prepared by dissolving the phospholipids in chloroform. These solutions were dried out under a stream of nitrogen in a fume cupboard. The vial containing the phospholipids was then placed under vacuum for 24 hours to ensure removal of any traces of chloroform. Dried phospholipid was diluted to $0.2 \mathrm{mg} \mathrm{ml}^{-1}$ in TBS, followed by sonication for 40 minutes. The multilamellar vesicles formed during this process were then manually extruded through an Avanti Polar Lipid mini extruder 10-12 times containing a $50 \mathrm{~nm}$ polycarbonate membrane and filter to create small unilamellar vesicles (SUV), with a diameter $\leq 70 \mathrm{~nm}$ [28]. This technique is commonly used for the preparation of SUVs suitable for the formation of SLBs on silicon dioxide $\left(\mathrm{SiO}_{2}\right)$ surface $[28,29]$.

\section{Electrochemical Impedance Spectroscopy}

Impedance experiments were performed at room temperature $\left(22 \pm 1^{\circ} \mathrm{C}\right)$ with a Gamry Interface1000 potentiostat (Gamry, USA). The mentioned temperature was selected as it is well above phase transition temperature of all phospholipids, ensuring all phospholipids were in the liquid-crystalline phase [3032]. The electrochemical data were obtained using a conventional three-electrode arrangement, consisting in a $\mathrm{SiO}_{2}$ /gold $(\mathrm{Au})$-coated quartz crystal working electrode (area $=1.54 \mathrm{~cm}^{2}$, Q-sense, Sweden), a platinum mesh as the counter electrode, and $\mathrm{Ag} / \mathrm{AgCl}, 3 \mathrm{M} \mathrm{NaCl}$ (ALS, Japan) as the reference electrode. The three electrodes were housed in a homemade batch cell designed to use the QCM-D crystals as the EIS working surface. The $\mathrm{SiO}_{2} / \mathrm{Au}-$ coated quartz crystal working electrode was selected for this study because it is the same surface used during the 


\section{Medicinal \& Analytical Chemistry International Journal}

QCM-D study previously reported by our group $[19,20]$. The impedance spectra were recorded between 0.1 and $105 \mathrm{~Hz}$ with an AC perturbation of $40 \mathrm{mV}$ and a DC bias $\mathrm{E}=0 \mathrm{~V}(\mathrm{vs} \mathrm{Ag} / \mathrm{AgCl}, 3 \mathrm{M} \mathrm{NaCl})$.

\section{Formation of Supported Lipid Bilayers}

Supported lipid bilayers were formed by the adsorption and fusion of SUVs onto a $\mathrm{SiO}_{2} / \mathrm{Au}$-coated quartz crystal following the procedure previously describe by Flynn, et al. [19]. TBS was pipetted into the batch cell and a potentiostatic EIS measurement was taken of the bare electrode. Then, the TBS was replaced with SUV phospholipid solution and a potentiostatic EIS measurement was taken every 5 minutes for 30 minutes until consistent values associated with those of a stable SLB were measured. The formed SLB was washed with TBS to remove any partially or weakly bound vesicles.

\section{Data Analysis}

The EIS data was analysed using Gamry Echem Analyst software (Gamry, USA) and the data was modeled using the electrical circuits shown in Figure 1. This circuit was used in a previous EIS study and proved to be a suitable model for the study of $\mathrm{SLBs}_{\mathrm{SiO}} / \mathrm{Au}$-coated quartz crystal sensors [21]. Constant phase elements (CPEs) are used in this circuit to account for any in homogeneity of both the $\mathrm{SiO}_{2}$ surface and SLBs [21]. The CPE is an electric element, in which impedance is defined:

$$
Z_{C P E}=\frac{1}{\left[Q(j \omega)^{\alpha}\right]}
$$

Where $Q$ is the parameter related to the electrode capacitance $\left(\mathrm{F} \mathrm{s}^{\alpha-1} \mathrm{~cm}^{-2}\right), \omega$ is the cyclic frequency, $\mathrm{j}^{\alpha}$ is a complex number $=\cos (\alpha \pi / 2)-j \sin (\alpha \pi / 2)$, and $\alpha$ is the constant phase exponent $(0<\alpha<1)$ related to the deviation of the straight capacitive line from $90^{\circ}$ by an angle $=90^{\circ}(1-\alpha)$. This constant phase exponent can be used as an indicator of the membrane heterogeneity. When $\alpha$ is equal to 0.5 , it corresponds to a purely diffusive process, and when $\alpha=1$, the CPE corresponds to an ideal capacitor [21].

Following the formation of the SLB on top of the $\mathrm{SiO}_{2}$ surface, an additional impedance element was added between the resistance of the electrolyte solution $\left(R_{s}\right)$ and the impedance of the $\mathrm{SiO}_{2}$-electrolyte interface in the circuit represented in Figure 1, to account for the impedance of the formed SLB. This impedance element consists of a resistance element representing the membrane resistance $\left(R_{m}\right)$ in parallel to the constant phase element of the membrane $\left(\mathrm{CPE}_{\mathrm{m}}\right)$.

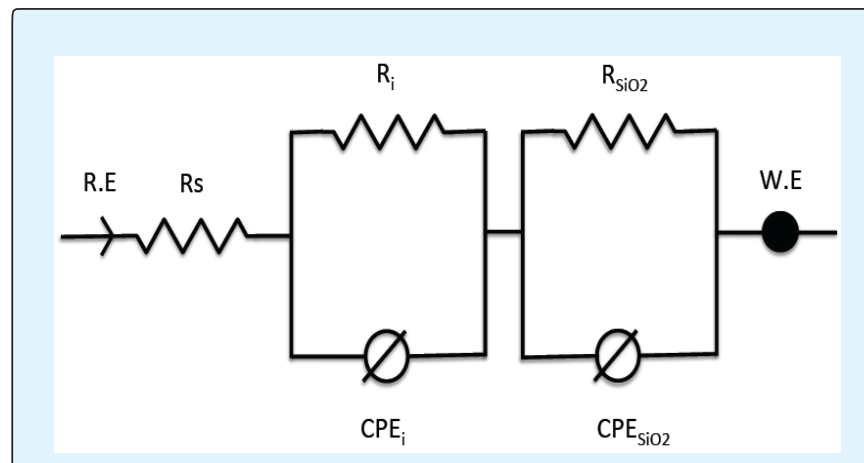

Figure 1: Equivalent circuit employed to fit EIS results. The circuit represents the $\mathrm{SiO}_{2}$-coated gold electrode before the formation of a SLB. It consists of three impedance elements connected in series, representing the resistance of the electrolyte solution $\left(R_{s}\right)$, impedance of the $\mathrm{SiO}_{2}$-electrolyte interface $\left(\mathrm{R}_{\mathrm{i}}\right.$ in parallel with $\mathrm{CPE}_{\mathrm{i}}$ ) and impedance of the $\mathrm{SiO}_{2}$ coating on the electrode surface $\left(\mathrm{R}_{\mathrm{SiO} 2}\right.$ in parallel with $\left.\mathrm{CPE}_{\mathrm{SiO} 2}\right)$.

\section{Results and Discussion}

Figure 2 shows Bode plots recorded for $\mathrm{SiO}_{2} / \mathrm{Au}$ coated quartz crystal working electrodes before and after modification with POPC SLB or POPC mixed with anionic phospholipids SLBs. Prior to the formation of the SLBs, the impedance spectra of the bare $\mathrm{SiO}_{2} / \mathrm{Au}$ electrode was measured $(n=10)$ to determine the baseline values of both the $\mathrm{SiO}_{2}$ coating and its interface resistance and capacitance. Following SLB formation, the $\mathrm{CPE}_{\mathrm{i}}$ parameter was fixed to determine the $\mathrm{R}_{\mathrm{m}}$ and $\mathrm{CPE}_{\mathrm{m}}$. Following DHA treatment parameters, $\mathrm{CPE}_{\mathrm{i}}, \mathrm{R}_{\mathrm{i}}, \mathrm{CPE}_{\mathrm{SiO} 2}$ and $\mathrm{R}_{\mathrm{Si} 02}$ were all fixed to see the changes in $\mathrm{R}_{\mathrm{m}}$ and $\mathrm{CPE}_{\mathrm{m}}$ as a consequence of DHA incorporation. The experimental $\mathrm{CPE}_{\mathrm{m}}, \alpha_{\mathrm{m}}$, and $\mathrm{R}_{\mathrm{m}}$ values were introduced in the EChem Analyst ${ }^{\circledR}$ software to calculate the true membrane capacitance, $\mathrm{C}_{\mathrm{m}}$, and the obtained values are reported in the different tables below $(\mathrm{n}=4)$. 

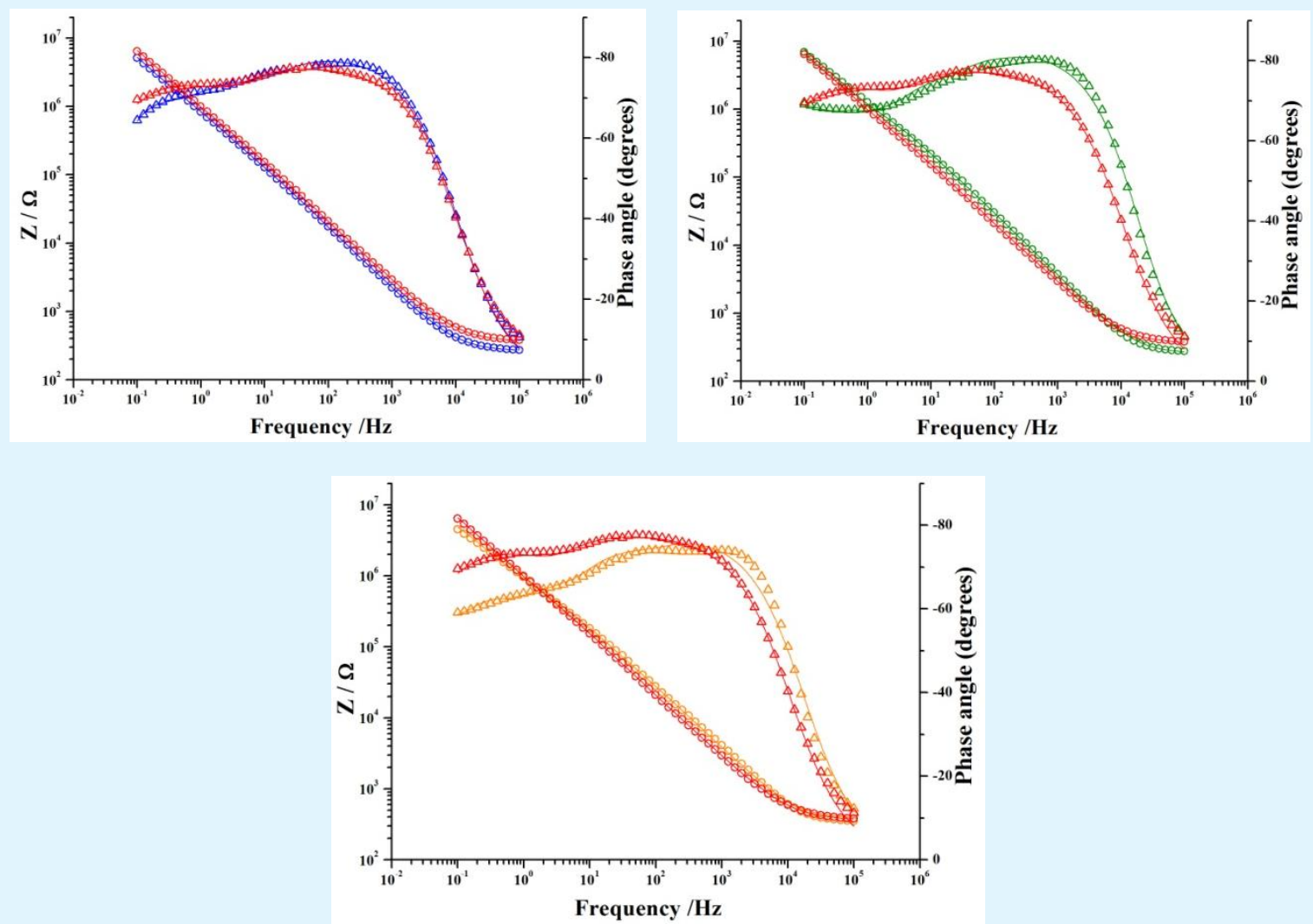

Figure 2: Impedance spectra in $10 \mathrm{mM}$ TBS over a frequency range of $0.1-10^{5} \mathrm{~Hz}$ for the $\mathrm{SiO}_{2} / \mathrm{Au}$ working electrode before (red) and after formation of POPC (blue), POPC-PI (9:1) (orange), and POPC-PS (9:1) (green) SLBs. The symbols represent the impedance (open circles) and the phase angle (open triangle). The solid lines are the results of a fitting procedure using the equivalent circuit shown in Figure 1.

\begin{tabular}{|c|c|c|c|c|}
\hline \multirow{2}{*}{ SLB } & & \multicolumn{3}{|c|}{ DHA Conc. } \\
\hline & & $50 \mu \mathrm{M}$ & $100 \mu \mathrm{M}$ & $200 \mu \mathrm{M}$ \\
\hline \multirow[t]{2}{*}{ POPC $^{b}$} & $h_{\mathrm{i}}(\mathrm{nm})$ & $10 \pm 1$ & $10 \pm 2$ & $9.8 \pm 1$ \\
\hline & $h_{\mathrm{f}}(\mathrm{nm})$ & $10 \pm 1$ & $96 \pm 33$ & $82 \pm 22$ \\
\hline \multirow[t]{2}{*}{ POPC:PI (9:1) } & $h_{\mathrm{i}}(\mathrm{nm})$ & $10 \pm 6.3$ & $9.9 \pm 2.9$ & $10 \pm 3.1$ \\
\hline & $h_{\mathrm{f}}(\mathrm{nm})$ & $7.1 \pm 2.1$ & $7.2 \pm 3.8$ & $7.2 \pm 3.7$ \\
\hline \multirow[t]{2}{*}{ POPC:PS (8:2) } & $h_{\mathrm{i}}(\mathrm{nm})$ & $6.8 \pm 0.76$ & $5.7 \pm 0.73$ & $5.1 \pm 2.3$ \\
\hline & $h_{\mathrm{f}}(\mathrm{nm})$ & $9.4 \pm 2.9$ & $21 \pm 6.8$ & $21.9 \pm 14$ \\
\hline \multirow[t]{2}{*}{ POPC:PS (9:1) } & $h_{\mathrm{i}}(\mathrm{nm})$ & $4.7 \pm 0.90$ & $7.8 \pm 1.5$ & $6.2 \pm 1.6$ \\
\hline & $h_{\mathrm{f}}(\mathrm{nm})$ & $10.0 \pm 6.5$ & $18.9 \pm 5.9$ & $53.4 \pm 22.6$ \\
\hline \multirow[t]{2}{*}{ POPC:PS (8:2) $\left(\mathrm{CaCl}_{2}\right)^{c}$} & $h_{\mathrm{i}}(\mathrm{nm})$ & $13 \pm 4.7$ & $13 \pm 4.3$ & $12.9 \pm 2.4$ \\
\hline & $h_{\mathrm{f}}(\mathrm{nm})$ & $23.6 \pm 5.13$ & $51.4 \pm 14.5$ & $59.1 \pm 11.0$ \\
\hline \multirow[t]{2}{*}{ POPC:PS (9:1) $\left(\mathrm{CaCl}_{2}\right)^{c}$} & $h_{\mathrm{i}}(\mathrm{nm})$ & $9.1 \pm 3.6$ & $9.9 \pm 2.4$ & $8.0 \pm 2.2$ \\
\hline & $h_{\mathrm{f}}(\mathrm{nm})$ & $14.2 \pm 2.0$ & $16.6 \pm 1.47$ & $941+12$ \\
\hline
\end{tabular}

Table 1: Thickness of the SLBs in the presence and absence of DHA .

${ }^{a}$ Data obtained from viscoelastic modeling (Voigt-based modeling) using QTools ${ }^{\circledR}$ (Q-sense) software (mean \pm SEM) in the absence $\left(h_{i}\right)$ and presence $\left(h_{f}\right)$ of DHA(n $\left.=4\right) .{ }^{b}$ Data obtained from reference ${ }^{20}$. $c$ Values obtained in the presence of 2 $\mathrm{mmol} \mathrm{CaCl}_{2}$. 


\section{Medicinal \& Analytical Chemistry International Journal}

The $\mathrm{SiO}_{2} / \mathrm{Au}-\mathrm{QCM}$ sensor surfaces are commonly used for SLBs formation and evaluation with a QCM instrument, as reported previously for our group $[19,20]$. Therefore, the use of the same surface as the working electrode in this work provides certainty about the formation and stability of the SLBs. In addition, it permits the comparison of the EIS results with those previously obtain with the use of QCM-D. It is worth notice that although the membrane thickness $(h)$ values were previously presented, they were recalculated in this work to account for a final rinsing step with TBS, which is mandatory after the addition of DHA. To this end, the Voigt-based model was used to determine the thickness of the SLBs and the values are reported in Table 1. For this calculation, the fluid density and viscosity were fixed at $1.0 \times 10^{3} \mathrm{~kg} \mathrm{~m}^{-3}$ and $1.0 \times 10^{-3} \mathrm{~kg} \mathrm{~ms}^{-1}$, respectively, as all experiments were conducted in aqueous solutions. The density of the lipid bilayer was fixed at $1.1 \times 10^{3} \mathrm{~kg} \mathrm{~m}^{-3}$, which is concurrent with previous studies $[20,33]$.

Table 2 shows the $\mathrm{C}_{\mathrm{m}}$ and resistance $\mathrm{R}_{\mathrm{m}}$ of POPC, POPC-PI 9:1, POPC-PS 8:2 and POPC-PS 9:1 SLBs, readily formed by vesicle adsorption, fusion and rupture on the $\mathrm{SiO}_{2} / \mathrm{Au}$ working electode. Despite the small differences observed in Figure 2, all SLBs formed showed a similar and highly reproducible $\mathrm{C}_{\mathrm{m}}$ value of $\approx 0.7 \mu \mathrm{F} \mathrm{cm} \mathrm{cm}^{-2}$, which is consistent with values previously reported in literature for similar systems [21,22,34-36].

\begin{tabular}{|c|c|c|}
\hline SLB & $\mathbf{R}_{\mathbf{m}}\left(\mathbf{M} \boldsymbol{\Omega} \mathbf{~ c m}^{2}\right)$ & $\mathbf{C}_{\mathbf{m}}\left(\boldsymbol{\mu} \mathbf{F} \mathbf{~ c m}^{-2}\right)$ \\
\hline POPC & $5.82 \pm 2.95$ & $0.69 \pm 0.01$ \\
\hline POPC-PI 9:1 & $9.43 \pm 0.48$ & $0.62 \pm 0.03$ \\
\hline POPC-PS 8:2 & $1.67 \pm 0.85$ & $0.69 \pm 0.04$ \\
\hline POPC-PS 9:1 & $4.85 \pm 1.85$ & $0.74 \pm 0.02$ \\
\hline POPC-PS 8:2 $\left(\mathbf{C a C l}_{\mathbf{2}}\right)^{a}$ & $9.60 \pm 3.09$ & $0.81 \pm 0.06$ \\
\hline POPC-PS 9:1 $\left(\mathbf{C a C l}_{\mathbf{2}}\right)^{a}$ & $14.3 \pm 5.62$ & $0.81 \pm 0.04$ \\
\hline
\end{tabular}

Table 2: Experimental resistance and capacitance values obtained for the different SLBs studied in this work ( $\mathrm{n}=10)$. ${ }^{a}$ resistance and capacitance values obtained in the presence of $2 \mathrm{mmol} \mathrm{CaCl}_{2}$.

Following SLB formation, 50, 100 and $200 \mu \mathrm{M}$ DHA was added into the electrochemical cell and left to interact with the SLBs for 2 hours. Then, the electrochemical cell was washed with TBS to remove any partially or weakly bound DHA molecules. Finally, the changes in the $C_{m}$ and $R_{m}$ of SLBs were monitored. It is important to note that the critical micellar concentration (CMC) of DHA is between 60-90 $\mu \mathrm{M}$ [37]. Therefore, at 50 $\mu \mathrm{M}$ DHA concentration, DHA exists as single lipid species. At $100 \mu \mathrm{M}$, the single lipid species will still predominantly exist, whilst at $200 \mu \mathrm{M}$, micellar DHA will be in excess [37].

The POPC SLB had an increase in $\mathrm{C}_{\mathrm{m}}$ following DHA treatments, with no significant difference between the three DHA concentrations (Table 3). This may be seen as a similar intake at all three DHA concentrations. However, the Voigt-based modeling to determine thickness (Table
1) showed no changes in the SLB thickness after the addition of $50 \mu \mathrm{M}$ DHA. However, a change was observed with larger DHA concentration. By using the equation 2 it is possible to calculate the change in the SLB dielectric properties $\left(\Delta \varepsilon_{\mathrm{m}}\right)$ :

$$
C_{m}=\frac{\varepsilon \varepsilon_{o}}{h}
$$

Where $\varepsilon$ is the dielectric constant of the bilayer (function of the frequency and membrane composition and structure), $\varepsilon_{0}$ is the dielectric permittivity of a vacuum $\left(9.8542 \times 10^{-1} 4 \mathrm{~F} \mathrm{~cm}^{-1}\right)$, and $h$ is the thickness of the dielectric sheet. From this equation it is apparent that the capacitance of the membrane will be affected by changes in both $h$ and $\varepsilon$ [38]. 


\section{Medicinal \& Analytical Chemistry International Journal}

\begin{tabular}{|c|c|c|c|c|}
\hline \multirow[t]{2}{*}{ SLB } & & \multicolumn{3}{|c|}{ DHA Conc. } \\
\hline & & $50 \mu \mathrm{M}$ & $100 \mu \mathrm{M}$ & $200 \mu \mathrm{M}$ \\
\hline \multirow{2}{*}{ POPC } & $\Delta R_{m}\left(\mathrm{k} \Omega \mathrm{cm}^{2}\right)$ & $-99.0 \pm 27.0$ & $-743 \pm 162$ & $-120 \pm 77.0$ \\
\hline & $\Delta \mathrm{C}_{\mathrm{m}}\left(\mathrm{nF} \mathrm{cm^{-2 }}\right)$ & $21.4 \pm 7.83$ & $14.5 \pm 6.15$ & $12.6 \pm 4.39$ \\
\hline \multirow{2}{*}{ POPC-PI (9:1) } & $\Delta R_{m}\left(\mathrm{k} \Omega \mathrm{cm}^{2}\right)$ & $-970 \pm 190$ & $-1250 \pm 368$ & $-1000 \pm 193$ \\
\hline & $\Delta \mathrm{C}_{\mathrm{m}}\left(\mathrm{nF} \mathrm{cm}^{-2}\right)$ & $8.94 \pm 4.59$ & $8.86 \pm 2.49$ & $13.7 \pm 4.09$ \\
\hline \multirow{2}{*}{ POPC-PS (8:2) } & $\Delta R_{m}\left(\mathrm{k} \Omega \mathrm{cm}^{2}\right)$ & $-197 \pm 83.9$ & $-225 \pm 24.0$ & $-60.2 \pm 33.4$ \\
\hline & $\Delta \mathrm{C}_{\mathrm{m}}\left(\mathrm{nF} \mathrm{cm}^{-2}\right)$ & $13.8 \pm 9.86$ & $48.8 \pm 12.4$ & $-7.43 \pm 1.01$ \\
\hline \multirow{2}{*}{ POPC-PS (9:1) } & $\Delta R_{m}\left(\mathrm{k} \Omega \mathrm{cm}^{2}\right)$ & $-1400 \pm 667$ & $-195 \pm 109$ & $-612 \pm 213$ \\
\hline & $\Delta \mathrm{C}_{\mathrm{m}}\left(\mathrm{nF} \mathrm{cm}^{-2}\right)$ & $59.5 \pm 6.08$ & $1.66 \pm 1.44$ & $18.9 \pm 9.00$ \\
\hline \multirow{2}{*}{ POPC-PS (8:2) (CaCl2)a } & $\Delta R_{m}\left(\mathrm{k} \Omega \mathrm{cm}^{-2}\right)$ & $-100 \pm 33.8$ & $478 \pm 322$ & $1000 \pm 466$ \\
\hline & $\Delta \mathrm{C}_{\mathrm{m}}\left(\mathrm{nF} \mathrm{cm}^{-2}\right)$ & $13.0 \pm 0.33$ & $20.7 \pm 4.45$ & $20.3 \pm 0.95$ \\
\hline \multirow{2}{*}{ POPC-PS (9:1) $\left(\mathrm{CaCl}_{2}\right)^{a}$} & $\Delta R_{m}\left(\mathrm{k} \Omega \mathrm{cm}^{-2}\right)$ & $-546 \pm 248$ & $-1000 \pm 586$ & $-314 \pm 47.0$ \\
\hline & $\Delta \mathrm{C}_{\mathrm{m}}\left(\mathrm{nF} \mathrm{cm}^{-2}\right)$ & $24.4 \pm 9.65$ & $5.37 \pm 2.03$ & $3.44 \pm 1.11$ \\
\hline
\end{tabular}

Table 3: Resistance and true capacitance changes of the SLBs in the presence of DHA.

${ }^{a}$ resistance and capacitance values obtained in the presence of $2 \mathrm{mmol} \mathrm{CaCl}_{2}$.

The increase in $\mathrm{C}_{\mathrm{m}}$ after the three DHA treatments could signify a decrease in thickness (moving the dielectric plates closer together). However, from Table 1 we can observe that the DHA treatments caused no modifications to the membrane thickness at $50 \mu \mathrm{M}$ DHA, but a more thick SLB at higher DHA concentrations. Therefore, using the equation 2 we hypothesize that this increase in $\mathrm{C}_{\mathrm{m}}$ is a consequence of an increase in the $\varepsilon_{\mathrm{m}}$ of the POPC SLB, consequence of an increase in charged DHA molecules inside the POPC SLB.

At $50 \mu \mathrm{M}$, the increase in $\varepsilon_{\mathrm{m}}$ may be a consequence of single lipid DHA being incorporated. This, in conjuction with the absence of change in the SLB $\Delta h$ at $50 \mu \mathrm{M}$, as estimated by the Voigt-based modelling, suggests the least incorporation of DHA (of the three DHA concentrations), and was supported by our previous work that reported the lowest increase in mass and reduction in visco elasticity following $50 \mu \mathrm{M}$ DHA. At 100 and $200 \mu \mathrm{M}$ DHA, the further increases in $\Delta \varepsilon_{\mathrm{m}}$ may be a consequence of the further incorporation of DHA via single lipid species, micelles or both within the POPC SLB. Thid, et al. predicted that single lipid DHA was incorporated into POPC SLB at all three DHA concentrations (also 50, 100 and $200 \mu \mathrm{M}$ ), however, above CMC the process was predicted to be facilitated by micelles.

The changes in $R_{m}$ may provide further insights into the electrochemical changes occurring inside the POPC SLB, following DHA treatment. The POPC SLBs resistance decreased following treatment with all three DHA concentrations. The changes in resistance differed with DHA concentrations, with the largest change seen at 100 $\mu \mathrm{M}$ DHA and smaller and similar changes seen at 50 and $200 \mu \mathrm{M}$ DHA (Table 3). A reduction in resistance may indicate a disruption of the lipid order of the SLB, allowing more ions to pass through. It is known that DHA is able to change the viscoelastic properties (including increased fluidity) of the POPC SLB, a likely consequence of DHA ability to exist in multiple configurations as a consequence of its six double bonds [2,39]. This is supported by studies that reported how the presence of DHA in the $s n-2$ position of PC molecules increased the molecular area by 11 and 13 per cent when compared to 16:0-18:1 PC and 18:0-18:1 PC, respectively [40,41]. Therefore, we can hypothesise that DHA may be able to produces pacers between the POPC molecules or even nano-pores via DHA-rich domains, $[15,42,43]$ allowing for the easier movements of ions across the bilayer, that may result in the observed reduction in resistance. However, from this study alone, the exact mechanism cannot be predicted. The unexpected lower $\Delta \mathrm{R}_{\mathrm{m}}$ at $200 \mu \mathrm{M}$ may be a consequence of POPC (rich in DHA) SLB lipid protrusions. This idea is further supported by the largest increase in $h$ and decreases in visco elasticity of the mentioned SLB previously reported.

The properties of POPC-PI9:1 SLB following DHA treatment was also evaluated (Table 3). This molar per cent of PI was chosen on the basis that neuronal plasma membranes contain approximately 10\% PI. The POPC-PI 9:1 SLB shows no significant changes in $C_{m}$ and $R_{m}$ 


\section{Medicinal \& Analytical Chemistry International Journal}

following DHA treatment. This result, together with the no significant variation in the SLB $h$ (Table 1), may indicate that the membrane $\varepsilon_{\mathrm{m}}$ remains constant and independent on the DHA concentration present in the solution. This observation can only indicate a saturation effect, which indicates that our previous assumption of DHAphospholipid substitution/rearrangement process may be inaccurate.

Two POPC-PS SLBs were formed (8:2 and 9:1 mol per cent ratios) and $\Delta \mathrm{C}_{\mathrm{m}}$ and $\Delta \mathrm{R}_{\mathrm{m}}$ responses to DHA treatment measured (Table 3). These two ratios were selected as it is known that PS accounts for between 12 and $22 \%$ of the phospholipid content of nervous tissue [44]. The POPC-PS 8:2 SLB $\Delta \mathrm{C}_{\mathrm{m}}$ differed between the three DHA treatments, with the largest $\Delta \mathrm{C}_{\mathrm{m}}$ seen at $100 \mu \mathrm{M}$, followed by $50 \mu \mathrm{M}$, and a negative $\Delta \mathrm{C}_{\mathrm{m}}$ seen following the addition of $200 \mu \mathrm{M}$ DHA. The $\Delta h$ values for the POPC-PS 8:2 SLB were similar and independent to the DHA concentration above $100 \mu \mathrm{M}$ DHA, with a lower $\Delta h$ at $50 \mu \mathrm{M}$ DHA concentration. Therefore, using equation 2 , we can estimate that the $\Delta \varepsilon_{\mathrm{m}}$ at $100 \mu \mathrm{M}$ will be the largest. We can also predict the negative $\Delta \mathrm{C}_{\mathrm{m}}$ at $200 \mu \mathrm{M}$ is not only a consequence of the increase in $h$, but also a net decrease in $\varepsilon_{\mathrm{m}}$. Based on the $\Delta h$ we can assume the smallest $\Delta \varepsilon_{\mathrm{m}}$ occurred at $50 \mu \mathrm{M}$, which is supported by our previous QCM-D study that showed the lowest DHA incorporation at $50 \mu \mathrm{M}$, of the three concentrations.

Our previous QCM-D study reported reduced DHA incorporation at all DHA concentrations, for both POPCPS SLBs, compared to the POPC SLB. A consequence of the PS molecules, which are reported to distribute evenly throughout the POPC bilayer, is to provide a negatively charged to the SLB surface, which would exhibit repulsive forces with the anionic DHA $[19,45]$. It was reported that the POPC-PS 8:2 SLB reached an increase in mass of only $7 \%$ (to that of the POPC SLB, respectively) following 50 $\mu \mathrm{M}$ DHA. This supports the theory that a negatively charged SLB results in repulsion with anionic DHA species and justifies the lowest $\Delta \varepsilon_{\mathrm{m}}$ at $50 \mu \mathrm{M}$ DHA observed. The largest $\Delta \varepsilon_{\mathrm{m}}$ occurs following the addition of $100 \mu \mathrm{M}$ DHA. This $\Delta \varepsilon_{\mathrm{m}}$ mirrored our previous study that also reported the largest mass increase following the addition of the same DHA concentration. Meanwhile, the POPC-PS 8:2 SLBs tight lipid packing (due to PS's condensing effect) supports the hypothesis of an exchange process at high DHA concentrations. Our previous work showed that the POPC-PS 8:2 SLB following $200 \mu \mathrm{M}$ resulted in a more pronounced rearrangement event and a lower overall mass increase, compared to $100 \mu \mathrm{M}$. Therefore, the $\Delta \varepsilon_{\mathrm{m}}$ value (as estimated by $\Delta \mathrm{C}_{\mathrm{m}}$ and $\Delta h$ ) gives further insights into the different exchange or rearrangement mechanism that occurred to the POPC-PS 8:2 SLB at $200 \mu \mathrm{M}$, when micelles were present in excess. Potentially additional transfer between the POPC-PS 8:2 SLB and DHA micelles may have resulted in the significant loss of phospholipid species, accounting for an overall lower $\Delta \varepsilon_{\mathrm{m}}$ yet similar $\Delta h$, compared to $100 \mu \mathrm{M}$.

The POPC-PS 8:2 SLB resulted in a reduction in resistance following 50, 100 and $200 \mu \mathrm{M}$ DHA with the largest changes seen at 50 and $100 \mu \mathrm{M}$ DHA and a significantly smaller change seen following $200 \mu \mathrm{M}$ (Table 3 ). Therefore, the largest resistance changes occurred when the single lipid DHA species existed alone $(50 \mu \mathrm{M})$ or in excess $(100 \mu \mathrm{M})$, whilst when micellar DHA existed in excess $(200 \mu \mathrm{M})$ the resistance changes were less pronounced and in the same order of magnitude as that observed with POPC.

The POPC-PS 9:1 SLB resulted in significantly different $\Delta \mathrm{C}_{\mathrm{m}}$ values at all three DHA concentrations, with the largest change at $50 \mu \mathrm{M}$ followed by $200 \mu \mathrm{M}$ and the lowest $\Delta \mathrm{C}_{\mathrm{m}}$ value at $100 \mu \mathrm{M}$ (Table 3). The POPC-PS 9:1 SLBs $h$ increased with increasing DHA concentration (Table 1). This data allows us to estimate the $\Delta \varepsilon_{\mathrm{m}}$ values following DHA treatment and therefore the changes occurring in the SLB. Based on these data it could be speculated that more DHA was incorporated at $50 \mu \mathrm{M}$ DHA than initially predicted, however the QCM-D changes in frequency did not demonstrate this alone. Our previous QCM-D study showed that the POPC-PS 9:1 SLB had a slight decrease in mass value following the addition of 50 $\mu \mathrm{M}$, which was assumed to represent a small or zero incorporation of single lipid DHA. However, in light of the impedance data, it is more likely that the POPC-PS 9:1 SLB incorporates DHA molecules following $50 \mu \mathrm{M}$ DHA treatment. The calculated increase in $\varepsilon_{\mathrm{m}}$ after the addition of $50 \mu \mathrm{M} \mathrm{DHA}$, is thought to be not only a consequence of the incorporation of this free fatty acid into the SLB but also from the increase in SLB thickness after the mentioned addition. Therefore, the small decrease in mass value may be the result of a small substitution event and the subsequent removal of phospholipid species in exchange for DHA molecules.

We can predict that the smaller changes in $\mathrm{C}_{\mathrm{m}}$ with the addition of $100 \mu \mathrm{M}$ DHA are not only a consequence of the increase in $h$ but also a reduced increase in $\varepsilon_{\mathrm{m}}$, compared to $50 \mu \mathrm{M}$ DHA. Meanwhile, based on the second largest $\Delta \mathrm{C}_{\mathrm{m}}$ and largest reported $\Delta h$ at $200 \mu \mathrm{M}$ DHA, we can 
predict the largest $\Delta \varepsilon_{\mathrm{m}}$ at this concentration. At $100 \mu \mathrm{M}$ DHA we had previously reported an equal change in frequency and dissipation to $200 \mu \mathrm{M}$ DHA, however, the change in $\mathrm{C}_{\mathrm{m}}$ and then calculated change in $\varepsilon_{\mathrm{m}}$ is not mirroring this. It was previously predicted the largest rearrangement process occurred at $200 \mu \mathrm{M}$ DHA, indicating a larger incorporation of DHA at $200 \mu \mathrm{M}$, which is supported by this impedance data.

The lower PS content of the POPC-PS 9:1 SLB would reduce the negative SLB surface charge and the condensing effect. This could mean two things, i) less repulsion between the negatively charged SLB and anionic DHA and ii) the reduced condensing effect could allow for more incorporation of DHA. Interestingly, when comparing the two POPC-PS SLBs following $100 \mu \mathrm{M}$, we can predict a different $\Delta \varepsilon_{\mathrm{m}}$, as they both have a similar $\Delta h$ (with the exception of POPC-PS 9:1 at $200 \mu \mathrm{M}$ ) yet their $\Delta \mathrm{C}_{\mathrm{m}}$ values were significantly different. It is predicted that the POPC-PS 9:1 SLB would have increased DHA incorporation due to the reduced PS content and the reasons mentioned above. This theory was not reflected by larger $\Delta \mathrm{C}_{\mathrm{m}}$ and $\Delta \varepsilon_{\mathrm{m}}$ values at $100 \mu \mathrm{M}$ for the POPC-PS 9:1 SLB. As stated earlier, a more pronounced rearrangement process was reported in the POPC-PS 9:1 SLB, following $100 \mu \mathrm{M}$ DHA treatment. This could indicate that the POPC-PS 9:1 SLB had a larger loss of phospholipid species, accounting for the POPC-PS 9:1 SLB smaller calculated $\Delta \varepsilon_{\mathrm{m}}$ at $100 \mu \mathrm{M}$ (when compared to the 8:2 molar ratio). In contrast, the estimated $\Delta \varepsilon_{\mathrm{m}}$ at $200 \mu \mathrm{M}$ was higher in the 9:1 SLB, compared to the 8:2 SLB. The reduced condensing effect may allow the POPC-PS 9:1 SLB to incorporate a larger amount of DHA when micelles are in excess.

Additional POPC-PS SLBs were formed in the presence of $\mathrm{Ca}^{2+}$. Calcium ions play an important role in the membrane stability and function in an in vivo membrane system. Studies have revealed that $\mathrm{Ca}^{2+}$ bridge the negatively charged carboxyl groups of neighboring PS molecules or phosphate moieties of PS or PC molecules, displacing water to form anhydrous PS- $\mathrm{Ca}^{2+}$ domains in the bilayer [46-49]. The $\mathrm{Ca}^{2+}$ also assists the formation of a stable POPC-PS SLB on the crystal surface, by providing a bridge between the PS head group and the negatively charged $\mathrm{SiO}_{2}$ surface [50]. The POPC-PS SLBs formed in the presence of $\mathrm{Ca}^{2+}$ produced similar final $\mathrm{C}_{\mathrm{m}}$ values to those formed in the absence of $\mathrm{Ca}^{2+}$ (Table 2).

The $\Delta \mathrm{C}_{\mathrm{m}}$ and $\Delta \mathrm{R}_{\mathrm{m}}$ responses of the two POPC-PS $\left(\mathrm{Ca}^{2+}\right)$ SLBs, following DHA treatment were also monitored
(Table 3). The POPC-PS 8:2 ( $\mathrm{Ca}^{2+}$ ) SLBs $\Delta \mathrm{C}_{\mathrm{m}}$ increased following all three DHA treatments. Results from Table 1 shows that the POPC-PS 8:2 $\left(\mathrm{Ca}^{2+}\right)$ SLB resulted in large increases in $h$ following DHA treatment above $100 \mu \mathrm{M}$ DHA (closer to those $\Delta h$ of the POPC SLB), which also increase with DHA concentration. This implies that the $\Delta \varepsilon_{\mathrm{m}}$ should also increases with increasing DHA concentration. Due to the similarity in the $\Delta \mathrm{C}_{\mathrm{m}}$ values to those observed for POPC SLB (Table 3), this result may indicate that a larger amount of DHA was incorporated into the POPC-PS 8:2 SLB $\left(\mathrm{Ca}^{2+}\right)$, compared to the POPCPS 8:2 SLB formed in the absence of $\mathrm{Ca}^{2+}$; and that the presence of $\mathrm{Ca}^{2+}$ caused a greater amount of DHA to be incorporated, more similar to the POPC SLB. This is consistent with previous QCM-D study, which reported that the POPC-PS 8:2 $\left(\mathrm{Ca}^{2+}\right)$ SLB had a significantly larger mass uptake and decrease in viscoelastic properties at all DHA concentrations, compared to the POPC-PS 8:2 SLB formed in the absence of $\mathrm{Ca}^{2+}$. As stated earlier, the presence of $\mathrm{Ca}^{2+}$ assists interactions between neighboring PS and PC molecules, and it leads to the formation of rigid $\mathrm{PS}_{-} \mathrm{Ca}^{2+}$ domains with reduced lateral diffusion of molecules and ions, and fluidic POPC phases. Therefore, the formation of these fluidic POPC phases within the POPC-PS 8:2 ( $\left.\mathrm{Ca}^{2+}\right)$ SLB may allow the increased incorporation of DHA, compared to the POPC-PS 8:2 SLB (formed in the absence of $\mathrm{Ca}^{2+}$ ) when the PS is distributed throughout the SLB causing a net negative charge. This provides further support to why the POPC-PS 8:2 $\left(\mathrm{Ca}^{2+}\right)$ SLB presents $\Delta \mathrm{C}_{\mathrm{m}}$ values that resemble those of the POPC SLB. However, our previous QCM-D study showed that a different mechanism of incorporation was occurring in the POPC-PS 8:2 ( $\left.\mathrm{Ca}^{2+}\right)$ SLB (above CMC), involving a rearrangement/substitution event, which was not reported to occur to the POPC SLB following DHA treatment.

The POPC-PS 8:2 ( $\left.\mathrm{Ca}^{2+}\right)$ SLB $\Delta \mathrm{R}_{\mathrm{m}}$ responses supported the theory of a different mechanism of DHA incorporation occurring, above CMC, with no significant difference to the $\Delta \mathrm{R}_{\mathrm{m}}$ following $50 \mu \mathrm{M}$ DHA treatment, compared to the POPC SLB or POPC-PS 8:2 SLB formed in the absence of $\mathrm{Ca}^{2+}$ (Table 3). However, following 100 and $200 \mu \mathrm{M}$ DHA the opposite pattern was observed to the other SLBs formed, with a resistance increase. This was the only SLB to respond in a resistance increase following DHA incorporation, which may indicate that the DHA is changing the lipid dynamics to produce a more resistive SLB. These $\Delta \mathrm{R}_{\mathrm{m}}$ responses in conjunction with the estimated $\Delta \varepsilon_{\mathrm{m}}$ and $\Delta h$, may indicate that the large DHA incorporation is resulting in a tighter and more ordered 


\section{Medicinal \& Analytical Chemistry International Journal}

POPC-PS $\left(\mathrm{Ca}^{2+}\right)$ 8:2 SLB. The increase in resistance may indicate that $\mathrm{Ca}^{2+}$ inhibits single lipid DHA to form wedges or spaces between phospholipids within the SLB. Alternatively, the incorporation of DHA may be dissociating the $\mathrm{PS}^{-\mathrm{Ca}^{2+}}$ domains, due to multiple DHA monomers or micelles ability to interact with $\mathrm{Ca}^{2+}$ via calcium coordination. If true, the PS molecules would move out of the domains and distribute across the SLB, resulting in a 'condensing' effect, as reported to occur in the POPC-PS SLBs formed in the absence of $\mathrm{Ca}^{2+}$. This would account for the increase in $\mathrm{R}_{\mathrm{m}}$ whilst also the increase in $\varepsilon_{\mathrm{m}}$ following 100 and $200 \mu \mathrm{M}$ DHA treatment. It is worth noting the dissociation of these anhydrous PS$\mathrm{Ca}^{2+}$ domains could allow an increase in water and solute into the POPC-PS $\left(\mathrm{Ca}^{2+}\right)$ 8:2 SLB, and therefore the increase in $\varepsilon_{\mathrm{m}}$ may not be related to DHA incorporation alone.

The POPC-PS 9:1 ( $\left.\mathrm{Ca}^{2+}\right)$ SLB also showed an increase in $\mathrm{C}_{\mathrm{m}}$ following all DHA treatments. The $\Delta \mathrm{C}_{\mathrm{m}}$ was the highest following $50 \mu \mathrm{M}$ DHA, with significantly lower $\Delta \mathrm{C}_{\mathrm{m}}$ reported at $100 \mu \mathrm{M}$ and $200 \mu \mathrm{M}$ DHA (Table 3). The $\Delta h$ following DHA treatment had no significant difference between 50 and $100 \mu \mathrm{M}$ and 50 and $200 \mu \mathrm{M}$, however, there was a significant difference between 100 and 200 $\mu \mathrm{M}$ DHA. Therefore, we can estimate the $\Delta \varepsilon_{\mathrm{m}}$ of the POPCPS 9:1 $\left(\mathrm{Ca}^{2+}\right) \mathrm{SLB}$, to be the largest at $50 \mu \mathrm{M}$ DHA, respective to the largest $\Delta C_{m}$ response. Based on the changes in $h$ and $\mathrm{C}_{\mathrm{m}}$ it is also predicted that the $\Delta \varepsilon_{\mathrm{m}}$ decreases with increasing DHA concentration. The higher $\Delta \varepsilon_{\mathrm{m}}$ predicted to occur at $50 \mu \mathrm{M}$ DHA provides further insights to understand previous QCM-D results. Our previous QCM-D study reported a small loss of mass following $50 \mu \mathrm{M}$ DHA treatment, which did not indicate an incorporation of DHA; instead, it suggested a small loss of phospholipid species. Similar to the POPC-PS 9:1 SLB formed in the absence of $\mathrm{Ca}^{2+}$, the impedance data provides evidence that single DHA molecules were effectively incorporated and are responsible for the increase of the $\varepsilon_{\mathrm{m}}$ value of the POPC-PS 9:1 $\left(\mathrm{Ca}^{2+}\right)$ SLB. Therefore, the loss of mass may be a consequence of a small rearrangement process.

Our previous QCM-D data also showed a significant difference in the POPC-PS 9:1 ( $\left.\mathrm{Ca}^{2+}\right)$ SLB mass uptake at all DHA concentrations. It was predicted that this could be due to an overall larger incorporation of DHA at the expense of phospholipid species, to form a DHA-rich SLB. Therefore, at $200 \mu \mathrm{M}$, the lower $\Delta \varepsilon_{\mathrm{m}}$ may indicate the significant loss of phospholipid species of the POPC-PS 9:1 $\left(\mathrm{Ca}^{2+}\right)$ SLB as a consequence of a substitution event between DHA micelles in solution and DHA-rich SLB. A similar behavior was previously hypothesised to occur to the POPC-PI 9:1 SLB. It is important to note, that the PS$\mathrm{Ca}^{2+}$ complexes, as reported to occur in the POPC-PS 8:2 $\left(\mathrm{Ca}^{2+}\right)$ SLB, do not form in the POPC-PS 9:1( $\left.\mathrm{Ca}^{2+}\right)$ SLB. Literature states that these PS- $\mathrm{Ca}^{2+}$ complexes do not form to a significant extent unless the PS fraction is above $17 \%$. Therefore, this SLB would behave more similar to those SLB formed in the absence of $\mathrm{Ca}^{2+}$, with the PS distributed evenly throughout the bilayer. In addition, the $\mathrm{Ca}^{2+}$ may interact with single lipid and micellar DHA in solution further reducing incorporation into the POPC-PS 9:1 $\left(\mathrm{Ca}^{2+}\right)$ SLB.

The addition of $\mathrm{Ca}^{2+}$ did not cause any significant difference to the POPC-PS 9:1 SLBs $\Delta \mathrm{R}_{\mathrm{m}}$ following DHA treatment compared to the POPC-PS 9:1 SLB formed in the absence of $\mathrm{Ca}^{2+}$. This indicates that a similar amount of lipid disruption, responsible for the decreases in resistance, occurred at all three DHA concentrations, and further supports the theory that the two POPC-PS 9:1 SLBs (formed in the presence and absence of $\mathrm{Ca}^{2+}$ ) behave similarly.

\section{Conclusion}

This study describes a detailed analysis of EIS measurements performed on POPC or POPC-PI and POPCPS mixed SLBs. By calculating the SLB $h$, a more detailed analysis of the electrochemical responses following DHA treatment was possible. Importantly, the interpretation of the EIS data allowed us to gain a more detailed understanding about the changes in dielectric properties of the SLBs following DHA treatment. It also highlights how the interpretation of the EIS data alone may lead to limited insights and conclusions, specifically in reference to changes in capacitance. For instance, using the $\Delta \mathrm{C}_{\mathrm{m}}$ and $\Delta h$ of the POPC SLBs it was possible to estimate that the $\Delta \varepsilon_{\mathrm{m}}$ increased with increasing DHA concentration, similar to the increasing mass uptake observed in our previous QCM-D studies. The POPC SLBs $\Delta \mathrm{R}_{\mathrm{m}}$ did not mirror the $\Delta \mathrm{C}_{\mathrm{m}}$ and $\Delta \varepsilon_{\mathrm{m}}$, with a smaller $\Delta \mathrm{R}_{\mathrm{m}}$ seen at $200 \mu \mathrm{M}$ DHA (compared to $100 \mu \mathrm{M}$ ), which may provide evidence to support the theory that $200 \mu \mathrm{M}$ DHA treatment results in the formation of worm-like protrusions, as previously reported.

The presence of PI or PS in the POPC SLB resulted in significantly different EIS responses. From the analysis of the POPC-PI 9:1 SLBs $\Delta \mathrm{C}_{\mathrm{m}}$ and $\Delta h$ a smaller estimated $\Delta \varepsilon_{\mathrm{m}}$ following DHA treatment (above CMC) was predicted, and 


\section{Medicinal \& Analytical Chemistry International Journal}

supports the hypothesis of a rearrangement process previously reported to occur. This rearrangement or exchange process is thought to be associated with the removal of phospholipid species that contain many dipole moments and interacting water molecules, in exchange for DHA molecules. The POPC-PI 9:1 SLB also presented the largest decreases in resistance following DHA treatment (of all SLBs formed) indicating that the presence of phosphatidylinositol-4-phosphate may assist lipid disruption responsible for reduced resistance, potentially a consequence of hydrophobic interactions between the polyunsaturated DHA molecules and $s n-2$ acyl chain of PI molecules. A rearrangement process was also predicted to occur in the POPC-PS SLBs following DHA treatment, above CMC. Interestingly, it was estimated the POPC-PS 8:2 SLB largest $\Delta \varepsilon_{\mathrm{m}}$ occurred following $100 \mu \mathrm{M}$ DHA, with a lower $\Delta \varepsilon_{\mathrm{m}}$ at $200 \mu \mathrm{M}$ DHA. This result highlights the need to consider to what extent DHA incorporation increases SLB capacitance, in relation to the decreases associated from the loss of phospholipid species. The POPC-PS 9:1 SLBs $\Delta \varepsilon_{\mathrm{m}}$ was estimated to increase with DHA concentration, interestingly, the $\Delta \mathrm{C}_{\mathrm{m}}$ at $50 \mu \mathrm{M}$ DHA provided potential evidence of a slight rearrangement process occurring below $\mathrm{CMC}$, which was not possible to determine from our previous QCM-D data alone.

The POPC-PS 8:2 SLB formed in the presence of $\mathrm{Ca}^{2+}$ resulted in comparable $\Delta \mathrm{C}_{\mathrm{m}}$ and $\Delta h$ to the POPC SLB, allowing us to estimate a similar $\Delta \varepsilon_{\mathrm{m}}$ for both SLBs. This may imply a similar amount of DHA was incorporated into the POPC-PS 8:2 $\left(\mathrm{Ca}^{2+}\right)$ SLB as in the POPC SLB. Our previous QCM-D study showed similar mass uptakes for the two SLBs; however, the POPC-PS 8:2 $\left(\mathrm{Ca}^{2+}\right)$ SLB was shown to involve a rearrangement process, which was not reported to occur in the POPC SLB. The POPC-PS 8:2 $\left(\mathrm{Ca}^{2+}\right)$ SLB was the only SLB to show an increase in $\mathrm{R}_{\mathrm{m}}$ following 100 and $200 \mu \mathrm{M}$ DHA, indicating a dramatic lipid restructure within the SLB. We hypothesize that it may be a consequence of breaking the $\mathrm{PS}-\mathrm{Ca}^{2+}$ complexes, and increasing the condensing affect that accompanies PS when it is distributed more evenly throughout the SLB. The POPC-PS 9:1 $\left(\mathrm{Ca}^{2+}\right)$ SLB resulted in more similar electrochemical behavior to that of the POPC-PI 9:1 SLB as is suspected to be a result of the PS- $\mathrm{Ca}^{2+}$ complexes not forming when a lower mol per cent of PS exists.

The study of model membranes will lead to a better understanding of the complex properties of plasma membranes. Understanding the unique properties of DHA within the plasma membrane and its functional consequence is of particular interest as DHA has been highlighted to have therapeutic potential to treat DHArelated brain deficiencies, such as depression, bipolar, [51] and attention deficient hyperactivity disorder $[52,53]$. Investigating the behaviour of DHA within the plasma membrane may also have critical importance in understanding the neuronal cell death by apoptosis associated with neurodegeneration, $[54,55]$ and may also provide insights into improving treatment for tumors by increasing cell susceptibility to drugs such as chemotherapy.

\section{References}

1. Stillwell W, Shaikh SR, Zerouga M, Siddiqui R, Wassall SR (2005) Docosahexaenoic acid affects cell signalling by altering lipid rafts. Reprod Nutr Dev 45(5): 559579.

2. Stillwell W, Wassall SR (2003) Docosahexaenoic acid: membrane properties of a unique fatty acid. Chem Phys Lipids 126(1): 1-27.

3. Colombo J, Carlson SE, Cheatham CL, Shaddy DJ, Kerling EH, et al. (2013) Long-term effects of LCPUFA supplementation on childhood cognitive outcomes. Am J Clin Nutr 98(2): 403-412.

4. Daiello LA, Gongvatana A, Dunsiger S, Cohen RA, Ott BR (2015) Association of fish oil supplement use with preservation of brain volume and cognitive function. Alzheimers Dement 11(2): 226-235.

5. Yurko-Mauro K, McCarthy D, Rom D, Nelson EB, Ryan AS, et al. (2010) Beneficial effects of docosahexaenoic acid on cognition in age-related cognitive decline. Alzheimers \& Dementia 6(6): 456-464.

6. Jump DB (2001) The Biochemistry of $n-3$ Polyunsaturated Fatty Acids. J Biol Chem 277(11): 8755-8758.

7. Stulnig TM, Berger M, Sigmund T, Raederstorff D, Stockinger H, et al. (1998) Polyunsaturated Fatty Acids Inhibit $\mathrm{T}$ Cell Signal Transduction by Modification of Detergent-insoluble Membrane Domains. JCB 143(3): 637-644.

8. Pardini RS (2006) Nutritional intervention with omega-3 fatty acids enhances tumor response to antineoplastic agents. Chem Biol Interact 162: 89-105. 


\section{Medicinal \& Analytical Chemistry International Journal}

9. Guffy MM, North JA, Burns CP (1984) Effect of Cellular Fatty Acid Alteration on Adriamycin Sensitivity in Cultured L1210 Murine Leukemia Cells. Cancer Res 44(5): 1863-1866.

10. Liu QY, Tan BKH (2000) Effects of cis-unsaturated fatty acids on doxorubicin sensitivity in P388/DOX resistant and P388 parental cell lines. Life Sci 67(10): 1207-1218.

11. Burns CP, Spector AA (1987) Membrane Fatty Acid Modification in Tumor Cells: A Potential Therapeutic Adjunct. Lipids 22(3): 178-184.

12. Armstrong VT, Brzustowicz MR, Wassall SR, Jenski LJ, Stillwell W (2003) Rapid flip-flop in polyunsaturated (docosahexaenoate) phospholipid membranes. Arch Biochem Biophys 414(1): 74-82.

13. Ellens H, Siegel DP, Alford D, Yeagle PL, Boni L, et al. (1989) Membrane Fusion and Inverted Phases. Biochemistry 28(9): 3692-3703.

14. Farooqui AA, Horrocks LA, Farooqui T (2000) Glycerophospholipids in brain: their metabolism, incorporation into membranes, functions, and involvement in neurological disorders. Chem Phys Lipids 106(1): 1-29.

15. Wassall SR, Stillwell W (2009) Polyunsaturated fatty acid-cholesterol interactions: Domain formation in membranes. Biochim Biophys Acta 1788(1): 24-32.

16. Ehringer W, Belcher D, Wassall SR, Stillwell WA (1990) comparison of the effects of linolenic and docosahexaenoic acids on phospholipid bilayers. Chem Phys Lipids 54(2): 79-88.

17. Onuki Y, Morishita M, Chiba Y, Tokiwa S, Takayama K (2006) Docosahexaenoic Acid and Eicosapentaenoic Acid Induce Changes in the Physcial Properties of a Lipid Bilayer Model Membrane. Chem Pharm Bull 54(1): 68-71.

18. Thid D, Benkoski JK, Svedhem S, Kasemo B, Gold J (2007) DHA-Induced Changes of Supported Lipid Membrane Morphology. Langmuir 23(11): 58785881.

19. Flynn KR, Martin LL, Ackland ML, Torriero AAJ (2016) Real-Time Quartz-Crystal Microbalance Monitoring of Free Docosahexaenoic Acid Interactions with

Angel A.J. Torriero, et al. Electrochemical Impedance Spectroscopy Study of the interaction of Supported Lipid Bilayers with Free Docosahexaenoic Acid. Med \& Analy Chem Int J 2018, 2(3): 000122.
Supported Lipid Bilayers. Langmuir 32(45): 1171711727.

20. Flynn KR, Sutti A, Martin LL, Leigh Ackland M, Torriero AAJ (2018) Critical effects of polar fluorescent probes on the interaction of DHA with POPC supported lipid bilayers. Biochim Biophys Acta 1860(5): 1135-1142.

21. Briand E, Zach M, Svedhem S, Kasemo B, Petronis S (2010) Combined QCM-D and EIS study of supported lipid bilayer formation and interaction with poreforming peptides. Analyst 135(2): 343-350.

22. Purrucker $\mathrm{O}$, Hillebrandt $\mathrm{H}$, Adlkofer K, Tanaka M (2001) Deposition of highly resistive lipid bilayer on silicon-silicon dioxide electrode and incorporation of gramicidin studied by ac impedance spectroscopy. Electrochim Acta 47(5): 791-798.

23. Chang WK, Wimley WC, Searson PC, Hristova K, Merzlyakov M (2008) Charaterization of antimicrobrial peptide activity by electrochemical impedance spectroscopy. Biochim Biophys Acta 1778(10): 2430-2436.

24. Nikolakopoulou Z, Shaikh MH, Dehlawi H, MichaelTitus AT, Parkinson EK (2013) The induction of apoptosis in pre-malignant keratinocytes by omega-3 polyunsaturated fatty acids docosahexaenoic acid (DHA) and eicosapentaenoic acid (EPA) is inhibited by albumin. Toxicology Letters 218(2): 150-158.

25. Ravacci GR, Brentani MM, Tortelli Jr T, Torrinhas RSMM, Saldanha T, et al. (2013) Lipid raft disruption by docosahexaenoic acid induced apoptosis in transformed human mammary luminal epithelial cells harboring HER-2 overexpression. J Nutr Biochem 24(3): 505-515.

26. Liu Y, Chen LY, Sokolowska M, Alsaaty S, MartinezAnton A, et al. (2014) The fish oil ingredient, docosahexaenoic acid, activates cytosolic phospholipase A2 via GPR120 receptor to produce prostaglandin E2 and plays an anti-inflammatory role in macrophages. Immunology 143(1): 81-95.

27. Wander RC, Du SH (2000) Oxidation of plasma proteins is not increased after supplementation with eicosapentaenoic and docosahexaenoic acids. The American Journal of Clinical Nutrition 72(3): 731737. 


\section{Medicinal \& Analytical Chemistry International Journal}

28. Reimhult E, Hook F, Kasemo B (2003) Intact Vesicle Adsorption and Supported Biomembrane Formation from Vesicles in Solution: Influence of Surface Chemistry, Vesicle Size, Temperature, and Osmotic Pressure. Langmuir 19(5): 1681-1691.

29. Ritcher R, Mukhopadhyay A, Brisson A (2003) Pathways of Lipid Vesicle Deposition on Solid Surfaces: A Combined QCM-D and AFM Study. Biophys J 85(5): 3035-3047.

30. O'Neill SD, Leopold AC (1982) Assessment of Phase Transitions in Soybean Membranes. Plant Physiol 70(5): 1405-1409.

31. Peng A, Pisal DS, Doty A, Balu-lyer SV (2012) Phosphatidylinositol induces fluid phase formation and packing defects in phosphatidylcholine model membranes. Chem Phys Lipids 165(1): 15-22.

32. Silvius JR (1982) Thermotropic Phase Transitions of Pure Lipids in Model Membranes and Their Modifications by Membrane Proteins. John Wiley \& Sons, Inc.: New York.

33. Losada-Perez $\mathrm{P}$, Khorshid M, Hermans C, Robijns T, Peeters M, et al. (2014) Melittin disruption of raft and non-raft-forming biomimetic membranes: A study by quartz crystal microbalance with dissipation monitoring. Colloids Surf B Biointerfaces 123: 938944.

34. Lin J, Szymanski J, Searson PC, Hristova K (2009) Effect of a Polymer Cushion on the Electrical Properties and Stability of Surface-Supported Lipid Bilayer. Langmuir 26(5): 3544-3548.

35. Lundgren A, Hedlund J, Andersson O, Branden M, Kunze A, et al. (2011) Resonance-Mode Electrochemical Impedance Measurements of Silicon Dioxide Supported Lipid Bilayer Formation and Ion Channel Mediated Charge Transport. Anal Chem 83(20): 7800-7806.

36. Dilger JP, McLaughlin SG, McIntosh TJ, Simon SA (1979) The dielectric constant of phospholipid bilayers and the permeability of membranes to ions. Science 206(4423): 1196-1198.

37. Namani T, Ishikawa T, Morigaki K, Walde P (2007) Vesicles from docosahexaenoic acid. Colloids and Surfaces 54(1): 118-123.

Angel A.J. Torriero, et al. Electrochemical Impedance Spectroscopy Study of the interaction of Supported Lipid Bilayers with Free Docosahexaenoic Acid. Med \& Analy Chem Int J 2018, 2(3): 000122.
38. Budvytyte R, Mickevicius M, Vanderah DJ, Heinrich F, Valincius G (2013) Modification of tethered bilayers by phospholipid exchange with vesicles. Langmuir 29(13): 4320-4327.

39. Feller SE, Gawrisch K, MacKerell AD (2001) Polyunsaturated Fatty Acids in Lipid Bilayers: Intrinisic and Environmental Contributions to Their Unique Physical Properties. J Am Chem Soc 124(2): 318-326.

40. Smaby JM, Momsen MM, Brockman HL, Brown RE (1997) Phosphatidylcholine Acyl Unsaturation Modulates the Decrease in Interfacial Elasticity Induced by Cholesterol. Biophys J 73(3): 1492-1505.

41. Koenig BW, Strey HH, Gawrisch K (1997) Membrane Lateral Compressibility Determined by NMR and XRay Diffraction: Effect of Acyl Chain Polyunsaturation. Biophys J 73(4): 1954-1966.

42. Wassall SR, Stillwell W (2008) Docosahexaenoic acid domains: the ultimate non-raft membrane domain. Chem Phys Lipids 153(1): 57-63.

43. Janke M, Herrig A, Austermann J, Gerke V, Steinem C, et al. (2008) Actin Binding of Ezrin Is Activated by Specific Recognition of PIP2-Functionalized Lipid Bilayers. Biochemistry 47(12): 3762-3769.

44. Sastry PS (1985) Lipid of nervous tissue: Composition and metabolism. Prog Lipid Res 24(2): 69-176.

45. Peitzsch RM, Eisenberg M, Sharp KA, McLaughlin S (1995) Calculations of the Electrostatic Potential Adjacent to Model Phospholipid Bilayers. Biophys J 68(3): 729-738.

46. Roux M, Bloom M (1991) Calcium binding by phosphatidylserine headgroups. Deuterium NMR study. Biophysical Journal 60(1): 38-44.

47. Feigenson GW (1989) Calcium Ion Binding between Lipid Bilayers: The Four-Component System of Phosphatidylserine, Phosphatidylcholine, Calcium Chloride, and Water. Biochemistry 28(3): 1270-1278.

48. Barnes JP, Freed JH (1998) Dynamics and Ordering in Mixed Model Membranes of Dimyristoylphosphatidylcholine and Dimyristoylphosphatidylserine: A 250-GHz Electron Spin Resonance Study Using Cholestane. Biophys J 75(5): 2532-2546. 
49. Dluhy RA, Cameron DG, Mantsch HH, Mendelsohn R (1983) Fourier Transform Infrared Spectroscopic Studies of the Effect of Calcium Ions on Phosphatidylserine. Biochemistry 22(26): 63186325.

50. Ritcher RP, Brisson AR (2005) Following the Formation of Supported Lipid Bilayers on Mica: A Study Combining AFM, QCM-D, and Ellipsometry. Bipphysical Journal 88(5): 3422-3433.

51. Alessandri JM, Guesnet P, Vancassel S, Astorg P, Denis I, et al. (2004) Polyunsaturated fatty acids in the central nervous system: evolution of concepts and nutritional implications throughout life. Reprod Nutr Dev 44(6): 509-538.

52. Richardson AJ, Puri BK (2002) A randomized doubleblind, placebo-controlled study of the effects of supplementation with highly unsaturated fatty acids on ADHD-related symptoms in children with specific learning difficulties. Prog Neuropsychopharmacol Biol Psychiatry 26(2): 233-239.

53. Calder P, Dangour A, Diekman C, Eilander A, Koletzko $B$, et al. (2010) Essential fats for future health. Proceedings of the 9th Unilever Nutrition Symposium, 26-27 May 2010. Eur J Clin Nutr 64: 113.

54. Soderberg M, Edlund C, Kristensson K, Daliner G (1991) Fatty Acid Composition of Brain phospholipids in Aging and in Alzheimer's Disease. Lipids 26(6): 421-425.

55. Suphioglu C, De Mel D, Kumar L, Sadli N, Freestone D, et al. (2010) The omega-3 fatty acid, DHA, decreases neuronal cell death in association with altered zinc transport. FEBS 584(3): 612-618. 